\title{
Effects of Changes in Apnea Time on the Clinical Status of Neonates on NIV-NAVA
}

\author{
Erica L Morgan, Kimberly S Firestone, Scott W Schachinger, and Howard M Stein
}

BACKGROUND: Apnea time allows the clinician to set a minimum spontaneous respiratory frequency when using noninvasive neurally-adjusted ventilatory assist (NIV-NAVA). Short apnea times may provide backup ventilation during periods of physiologic variability causing overventilation and suppression of spontaneous respiratory drive. Longer apnea times may allow more spontaneous ventilation but can result in insufficient respiratory support. The purpose of this study was to evaluate various apnea times in neonates on NIV-NAVA. METHODS: This was a 2-center, prospective, 1-factorial, interventional study of neonates $<30$ weeks gestational age on NIV-NAVA. Clinically important events and ventilator data were recorded for apnea times of $2 \mathrm{~s}$ and $5 \mathrm{~s}$ for $2 \mathrm{~h}$ each. RESULTS: 15 neonates $(26 \pm 1.6$ weeks gestational age, birthweight $893 \pm 202$ g) were studied. When compared to the 5-s apnea time, the 2-s apnea time showed increased switches into backup ventilation from 0.5 switches/min to 2.5 switches/min $(P<.001)$, and time spent in backup ventilation increased from $2 \% / \mathrm{min}$ to $9 \% / \mathrm{min}(P<.001)$. However, clinically important events decreased from 7 clinically important events per hour to 2 clinically important events per hour $(P<.001)$. Measured breathing frequency increased with the 2 -s apnea time but spontaneous breathing frequency, $\mathrm{F}_{\mathrm{IO}_{2}}$, peak and minimum electrical activity of the diaphragm, and peak pressure remained unchanged. CONCLUSION: Short apnea times resulted in more switches into backup ventilation and longer time in backup ventilation but promoted clinical stability with fewer clinically important events in neonates ventilated with NIV-NAVA. Key words: triggering; apnea; NAVA; neurally adjusted ventilatory assist; neonatology. [Respir Care 2019;64(9):1096-1100. ( 2019 Daedalus Enterprises]

\section{Introduction}

Noninvasive ventilation (NIV) of neonates is used in an effort to decrease the duration and intensity of invasive ventilatory support to minimize upper airway damage and

\footnotetext{
Drs Morgan and Stein are affiliated with the ProMedica Toledo Children's Hospital, Toledo, Ohio. Ms Firestone and Dr Schachinger are affiliated with the Akron Children's Hospital, Akron, Ohio. Dr Schachinger is affiliated with the Pediatrix Medical Group of Ohio, Akron, Ohio. Dr Stein is affiliated with the University of Toledo College of Medicine and Life Sciences, Toledo, Ohio.
}

Dr Stein and Ms Firestone have disclosed relationships with Getinge. Drs Morgan and Schachinger have disclosed no conflicts of interest.

Correspondence: Howard M Stein MD, Department of Neonatology, ProMedica Toledo Children's Hospital, 2142 North Cove Blvd, Toledo, Ohio 43606. E-mail: howardstein@bex.net.

DOI: $10.4187 /$ respcare.06662 decrease the likelihood of the neonate developing chronic lung disease or bronchopulmonary dysplasia. ${ }^{1}$ Several studies have postulated that increasing patient-ventilator synchrony may improve the quality of NIV. ${ }^{2}$

Noninvasive neurally-adjusted ventilatory assist (NIVNAVA) ventilation (Getinge, Germany, software version 7) utilizes a neural trigger that allows patients to control the initiation, size, and termination of each breath. ${ }^{3}$ The patients control the amount of pressure delivered by the ventilator using the individual electrical activity of the diaphragm $\left(\mathrm{EA}_{\mathrm{di}}\right)$ waveform to trigger-on and cycle-off each assisted breath, therefore providing truly synchronized and proportional assist. ${ }^{4}$ This EA $_{\mathrm{di}}$ signal is obtained from a specialized indwelling nasogastric feeding tube with embedded sensing electrodes called a NAVA catheter. When properly positioned, it can accurately and reliably trigger and cycle the ventilator breath, independent of airway leaks, potentially making it ideal for synchronizing NIV. ${ }^{3}$ The specialized NAVA catheter is positioned using 
the catheter-positioning screen. Catheter positioning and safety have been previously validated. ${ }^{5-7}$ NIV-NAVA, compared to conventional NIV, has been shown to lower $\mathrm{EA}_{\mathrm{di}}$, peak pressures, $\mathrm{F}_{\mathrm{IO}_{2}}$, and the frequency and length of desaturations, and to improve synchrony (consisting of trigger delays, excessive delivery of assist, wasted efforts, and auto-triggering). ${ }^{8,9}$

During NIV-NAVA, the ventilator gives a neurally triggered breath in proportion to and in synchrony with the $\mathrm{EA}_{\mathrm{di}}{ }^{4}$ If the neonate has a period of apnea lasting for a predetermined time (ie, apnea time), the ventilator no longer detects an $\mathrm{EA}_{\mathrm{di}}$ and goes into backup ventilation mode consisting of pressure control ventilation at a preset peak pressure and frequency. As soon as another $\mathrm{EA}_{\mathrm{di}}$ signal is detected, NIV-NAVA ventilation resumes. Apnea time therefore allows the clinician to set a minimum breathing frequency $\left(\mathrm{f}_{\mathrm{min}}\right)$. For example, an apnea time of $5 \mathrm{~s}$ provides a $f_{\min }$ of 12 breaths/min, an apnea time of $4 \mathrm{~s}$ provides a $\mathrm{f}_{\text {min }}$ of 15 breaths/min, $3 \mathrm{~s}$ provides a $\mathrm{f}_{\min }$ of 20 breaths/min, and $2 \mathrm{~s}$ provides a $\mathrm{f}_{\min }$ of 30 breaths/min. However, if the neonate is consistently breathing at $>30$ breaths/min, the apnea time setting becomes less important because there will be few, if any, respiratory pauses $>2 \mathrm{~s}$. Current practice in both neonatal ICUs participating in the study is to set the apnea time at $2 \mathrm{~s}$. This is justified with the thought that any neonate requiring noninvasive ventilation should have a $f_{\min }$ of at least 30 breaths $/ \mathrm{min}$. If the neonate is stable on $<30$ breaths $/ \mathrm{min}$, they are transitioned to CPAP.

Currently, there are no data on the optimal apnea time setting during NIV-NAVA ventilation for neonates. Idiopathic apnea of prematurity is a frequent problem in neonatal ICUs. Numerous interventions from manual stimulation to mechanical ventilation are required to avoid potential morbidity. Understanding apnea of prematurity compared to periodic breathing is important because overtreatment exposes neonates to the therapeutic interventions whereas prolonged periods of apnea followed by desaturation and bradycardia can lead to prolonged cerebral hypoxemia and a risk for adverse long-term neurodevelopmental outcomes. ${ }^{10}$ Choosing an optimal apnea time during NIV-NAVA ventilation is significant to minimize backup ventilation (ie, excessively short apnea time) during periods of normal physiologic respiratory variability and to prevent long periods of time without any spontaneous or backup ventilation (ie, excessively long apnea time).

In some neonates, when the ventilator delivers a backup breath, the diaphragm occasionally is stretched and generates an $\mathrm{EA}_{\mathrm{di}}$ signal. This is known as Head's paradoxical reflex. ${ }^{11,12}$ This reflex occurs when a ventilator-produced inflation leads to excitation of the inspiratory activity, which is sensed by the NAVA catheter as an $\mathrm{EA}_{\mathrm{di}}$ signal. This $\mathrm{EA}_{\mathrm{di}}$ is then detected by the NAVA catheter, which is

\section{QUICK LOOK}

\section{Current knowledge}

In neonates on noninvasive neurally adjusted ventilator assist (NIV-NAVA), apnea time provides a minimum breathing frequency during periods of spontaneous and backup ventilation. Setting the appropriate apnea time should result in fewer clinically important events without causing overtreatment of periodic breathing with mandatory backup ventilation.

\section{What this paper contributes to our knowledge}

This study reports that neonates on NIV-NAVA with a short apnea time switched into backup ventilation more often and spent more time in backup ventilation, but were clinically more stable compared to those on NIVNAVA with a longer apnea time.

falsely interpreted by the ventilator as a spontaneous breath. This causes the apnea time to be reset, resulting in the neonate going an unintentionally long period without ventilation. For example, an apneic neonate may have a backup breathing frequency set at 40 breaths $/ \mathrm{min}$. If the apnea time is $5 \mathrm{~s}$ and the backup breath stretches the diaphragm and generates an $\mathrm{EA}_{\mathrm{di}}$ signal, the apnea timer will reset and the neonate will receive no respiratory support for another $5 \mathrm{~s}$ until getting another backup breath, potentially generating another $\mathrm{EA}_{\mathrm{di}}$ signal and resetting the apnea timer. Therefore, despite the neonate being apneic, instead of being ventilated at 40 backup breaths/min, the neonate, due to Head's paradoxical reflex, can receive as few as 12 breaths/min (Fig. 1). This can result in insufficient respiratory support and clinical deterioration, including bradycardia and desaturations. It may therefore be important to keep the apnea time short to prevent these occasional periods of insufficient ventilatory support.

The goal of this study was to evaluate the effect of different apnea time settings. The null hypothesis was that a shorter apnea time would result in less clinically important events (ie, bradycardias and desaturations as defined in the methods section) without causing overtreatment of periodic breathing with mandatory backup ventilation. These results will assist the clinician in selecting an appropriate apnea time during NIV-NAVA in premature neonates to maximize normal respiratory variability and minimize potentially harmful prolonged respiratory pauses.

\section{Methods}

We performed a 2-center, prospective, 1-factorial, interventional study of neonates $<30$-weeks gestational age 


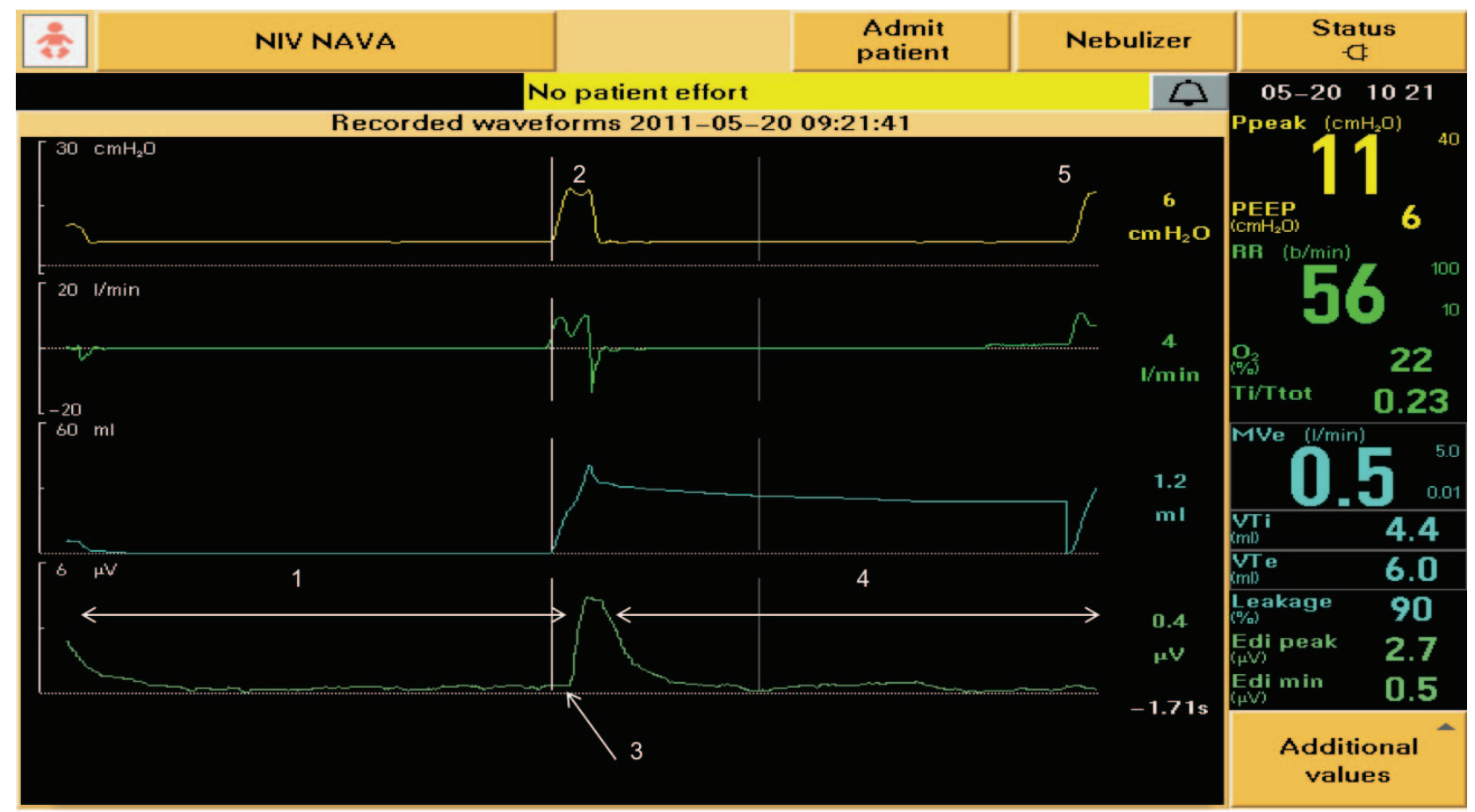

Fig. 1. Screenshot. Apnea time is set for $5 \mathrm{~s}$. After $5 \mathrm{~s}$ (1) the ventilator gives a backup breath (2). The backup breath stretches the diaphragm and causes an electrical activity of the diaphragm $\left(E A_{d i}\right)$ signal (3) that occurs after the backup breath. This is Head's paradoxical reflex. The apnea timer is restarted and, despite ongoing apnea, it takes another $5 \mathrm{~s}$ (4) before the ventilator gives another backup breath (5).

and $<1,500 \mathrm{~g}$ on NIV-NAVA using the Servo-i ventilator. We used the RAM cannula (Neotech, California) as the interface throughout the study. Institutional review board approval and informed consent were obtained. Subjects were randomized into a starting apnea time of either $2 \mathrm{~s}$ or $5 \mathrm{~s}$ for $2 \mathrm{~h}$, and then they were switched to the opposite setting for $2 \mathrm{~h}$. The NIV-NAVA and backup settings remained at the settings predetermined by the treating clinician prior to the study and were unchanged during the trial. Clinically important events, defined by heart rate $<90$ beats/min or oxygen saturation $<90 \%$ lasting $>10$ s, were collected by the clinician at the bedside. The $\mathrm{F}_{\mathrm{IO}_{2}}$, measured and spontaneous breathing frequency, peak and minimum $\mathrm{EA}_{\mathrm{di}}$, peak inspiratory pressure, switches/min to backup, and percentage/min in backup were downloaded from the ventilator. Statistical analysis of the effects of the 2 settings was performed using paired $t$ tests.

\section{Results}

A total of 15 neonates on NIV-NAVA with gestational age of $26 \pm 1.6$ weeks (range 23-28 weeks) and birthweight of $893 \pm 202 \mathrm{~g}$ (range 560-1,218 g) were studied at $15 \pm 16 \mathrm{~d}$ of life (range $4-68 \mathrm{~d}$ ) and weight of $921 \pm 208 \mathrm{~g}$ (range 485-1,275 g). Diagnoses were respiratory distress syndrome and apnea of prematurity; $73 \%$ received prenatal steroids, median Apgars were 5 (1 min) and 7 (5 min),
$80 \%$ received surfactant $(47 \%$ were intubated briefly for INSURE (Intubate, surfactant, extubate), 33\% were intubated for mechanical ventilation prior to NIV-NAVA), and all neonates were on caffeine. The practice in our neonatal ICUs is to start with CPAP in neonates $>25$ weeks old and then escalate to NIV-NAVA if there are ventilation concerns ( $\mathrm{pH}<7.2)$ or to INSURE if there are oxygenation concerns $\left(\mathrm{F}_{\mathrm{IO}_{2}}>35-40 \%\right)$. If these approaches fail, the neonate is intubated and mechanically ventilated. Neonates $<25$ weeks old (or others with respiratory failure in the delivery room) are intubated, given surfactant, and then weaned to extubation as rapidly as possible. Noninvasive ventilator settings at the time of the study included NAVA levels $1.1 \pm 0.8 \mathrm{~cm} \mathrm{H}_{2} \mathrm{O} / \mu \mathrm{V}$ (range 0.5-2.8 $\mathrm{cm} \mathrm{H}_{2} \mathrm{O} / \mu \mathrm{V}$ ), PEEP $7.9 \pm 1 \mathrm{~cm} \mathrm{H}_{2} \mathrm{O}$ (range 6-10 $\mathrm{cm} \mathrm{H}_{2} \mathrm{O}$, nasal interface RAM cannula), pressure limit $36 \pm 2 \mathrm{~cm} \mathrm{H}_{2} \mathrm{O}$ (range 35-40 $\mathrm{cm} \mathrm{H}_{2} \mathrm{O}$ ), backup pressure $21 \pm 4 \mathrm{~cm} \mathrm{H}_{2} \mathrm{O}$ (range 15-30 $\mathrm{cm} \mathrm{H}_{2} \mathrm{O}$ ); backup breathing frequency was $40 \pm 8$ breaths/min (range 3055 breaths/min), and baseline apnea times were $2 \pm 0.25 \mathrm{~s}$ (range 2-3 s). There were no catheter placement or migration issues during the study. All settings other than apnea time did not change throughout the study.

At 5-s versus 2-s apnea time, switches into back up increased from 0.5 switches $/ \mathrm{min}$ to 2.5 switches $/ \mathrm{min}$ $(P<.001)$, and time spent in backup increased from $2 \% / \mathrm{min}$ to $9 \% / \mathrm{min}(P<.001)$. However, there was a 


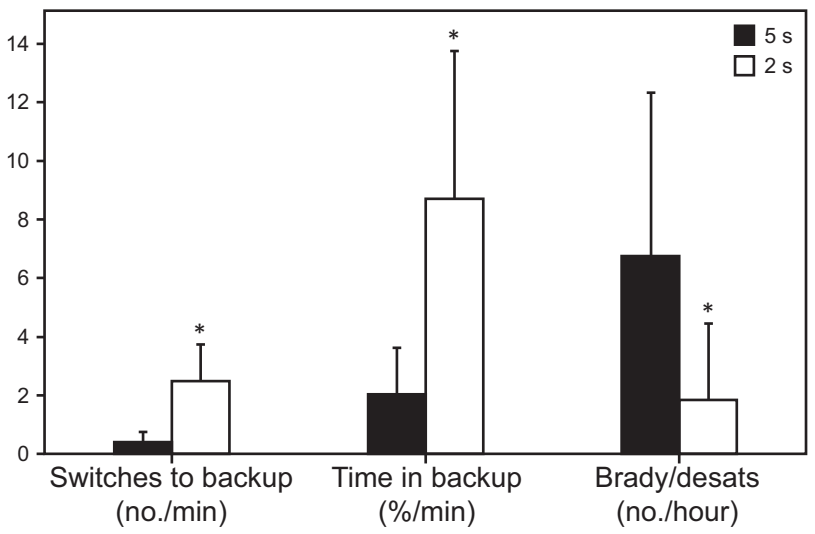

Fig. 2. Switches to backup and time spent in backup were higher with the 2-s apnea time compared to the 5-s apnea time. However, there were fewer clinically important events with the 2-s apnea time. Brady/desats $=$ bradycardia/desaturations. ${ }^{\star} P<.001$.

Table 1. Ventilator Data With 5-s vs 2-s Apnea Time

\begin{tabular}{|c|c|c|c|}
\hline & $\begin{array}{c}\text { 5-s } \\
\text { Apnea Time }\end{array}$ & $\begin{array}{c}\text { 2-s } \\
\text { Apnea Time }\end{array}$ & $P$ \\
\hline $\mathrm{F}_{\mathrm{IO}_{2}}$ & $0.25 \pm 0.07$ & $0.2 \pm 0.08$ & .22 \\
\hline $\begin{array}{l}\text { Frequency measured, } \\
\text { breaths/min }\end{array}$ & $56 \pm 9.6$ & $60 \pm 8.7$ & $<.001$ \\
\hline $\begin{array}{l}\text { Frequency spontaneous, } \\
\text { breaths/min }\end{array}$ & $55 \pm 10$ & $55 \pm 11$ & .67 \\
\hline $\mathrm{EA}_{\mathrm{di}}$ peak, $\mu \mathrm{V}$ & $8.9 \pm 2.8$ & $8.6 \pm 2.4$ & .27 \\
\hline $\mathrm{EA}_{\mathrm{di}}$ minimum, $\mu \mathrm{V}$ & $2.1 \pm 0.6$ & $2.2 \pm 0.6$ & .26 \\
\hline $\begin{array}{l}\text { Peak airway pressure, } \\
\mathrm{cm} \mathrm{H}_{2} \mathrm{O}\end{array}$ & $15.5 \pm 4.7$ & $15.6 \pm 4.3$ & .39 \\
\hline
\end{tabular}

Breathing frequency was significantly higher in the 2-s apnea time compared to the 5-s apnea time $(P<.001)$. All other variables were unchanged.

$\mathrm{EA}_{\mathrm{di}}=$ electrical activity of the diaphragm

decrease from 7 clinically important events per hour to 2 clinically important events per hour $(P<.001)$ during the 2-s apnea time (Fig. 2). Other measured variables were unchanged, except for the measured respiratory frequency, which increased on the 2-s apnea time (Table 1).

\section{Discussion}

This study demonstrates that neonates on NIV-NAVA with an apnea time of $2 \mathrm{~s}$ switched into backup ventilation more often and spent more time in backup ventilation, but were more clinically stable with fewer clinically important events compared to similar neonates with an apnea time of $5 \mathrm{~s}$. These results suggest premature neonates would benefit from apnea times set at $2 \mathrm{~s}$ compared to $5 \mathrm{~s}$ when receiving NIV-NAVA support.

Shorter apnea times raise a theoretical concern for oversupporting the neonate during times of normal physiologic respiratory variability. Supportive ventilation could contribute to hyperventilation, which would result in decreased respiratory drive. Preterm neonates have impaired ventilatory responses to $\mathrm{CO}_{2}$. They have a $\mathrm{CO}_{2}$ level below which apnea is triggered. ${ }^{13,14}$ Therefore, during periods of hyperventilation, more apnea can ensue. This was not seen in our study, in which $\mathrm{EA}_{\mathrm{di}}$ peak signals were assessed as a surrogate for respiratory drive. A decreased $\mathrm{EA}_{\mathrm{di}}$ peak and increased periods of apnea would correlate with decreased respiratory drive. This study showed comparable $\mathrm{EA}_{\mathrm{di}}$ levels suggesting no difference in respiratory drive. Even though neonates switched into backup more frequently and for longer periods, thus resulting in a higher measured respiratory frequency, both groups had spontaneous ventilation $>90 \%$ of the time. It is feasible that clinicians might overtreat apnea slightly to reduce the number of clinically important events in an attempt to improve clinical stability. This may be an acceptable tradeoff under the assumption of presumed harm without intervention from increased clinically important events. ${ }^{10}$

Longer apnea times raise a theoretical concern about undersupporting neonates, and this was borne out by the neonates having a lower measured respiratory frequency and more clinically important events with the 5-s apnea time. This suggests that the neonatal diaphragm is susceptible to Head's paradoxical reflex, which results in false neural triggering and a lower measured respiratory frequency. This enforces the need for short apnea times and higher $\mathrm{f}_{\min }$.

One of the shortcomings of NIV-NAVA technology is the inability to correctly identify spontaneous versus ventilator-derived inspiration from Head's paradoxical reflex. This signal may be misinterpreted by the ventilator software algorithm as spontaneous breathing and thus may reset the apnea timer. This can lead to prolonged periods of inadequate ventilation, further reinforcing the need for shorter apnea times.

Weaknesses of this study include only studying 2 apnea times. We chose $2 \mathrm{~s}$ because it is the shortest apnea time currently available in the ventilator software. We compared $5 \mathrm{~s}$ to $2 \mathrm{~s}$ because it is commonly used in the clinical setting. Apnea times $>5 \mathrm{~s}\left(\mathrm{f}_{\min }<12\right.$ breaths/min) were felt to put the subjects at unacceptable risk from prolonged hypoventilation. This study's sample size is too small to determine whether the choice of apnea time should be adjusted due to gestational age, weight, or disease state. Neonates were studied in two 2 -h periods, so it is unclear whether there is any long-term difference in outcomes when shorter or longer apnea times are used during NIVNAVA.

Neonates breathe in the physiologic range of $40-$ 60 breaths $/ \mathrm{min},{ }^{15}$ and it is possible that, in certain patients, such as extremely preterm neonates, the shortest apnea time of $2 \mathrm{~s}$ may not be sufficient. An apnea time of $2 \mathrm{~s}$ 


\section{Changes in Apnea Time in NIV-NAVA}

translates to a $\mathrm{f}_{\text {min }}$ of only 30 breaths/min, whereas an apnea time of $1 \mathrm{~s}$ would allow a $\mathrm{f}_{\min }$ of 60 breaths/min, which is more consistent with neonatal physiology. Future software updates that allow the user to reduce the apnea time in small increments from $2 \mathrm{~s}$ to $1 \mathrm{~s}$ may allow less mature and less stable babies to benefit from NIV-NAVA ventilation by providing a higher $\mathrm{f}_{\min }$ and more respiratory support when needed.

\section{Conclusions}

The results of this study suggest that short apnea times should be utilized for neonatal patients ventilated with NIV-NAVA to promote clinical stability and decrease the occurrence of clinically important events. Occasional false neural triggering due to Head's paradoxical reflex is a known limitation of NIV-NAVA that may lead to more pronounced periods of suboptimal ventilation if the apnea time is set at $5 \mathrm{~s}$ compared to $2 \mathrm{~s}$.

\section{REFERENCES}

1. Jobe AH, Ikegami M. Prevention of bronchopulmonary dysplasia. Curr Opin Pediatr 2001;13(2):124-129.

2. Lemyre B, Davis P, De Paoli A, Kirpalani H. Nasal intermittent positive pressure ventilation (NIPPV) versus nasal continuous positive airway pressure (NCPAP) for preterm neonates after extubation. Cochrane Database Syst Rev 2017;(2):CD003212.

3. Firestone KS, Beck J, Stein H. Neurally Adjusted ventilatory assist for noninvasive support in neonates. Clin Perinatol 2016;43(4):707-724.

4. Sinderby C, Beck J. Proportional assist ventilation and neurally adjusted ventilatory assist: better approaches to patient ventilator synchrony? Clin Chest Med 2008;29:329-342.
5. Duyndam A, Bol B, Kroon A, Tibboel D, Ista E. Neurally adjusted ventilatory assist: assessing the comfort and feasibility of use in neonates and children. Nursing in Critical Care 2013;18(2): 86-92.

6. Barwing J, Ambold M, Linden N, Quintel M, Moerer O. Evaluation of the catheter positioning for neurally adjusted ventilatory assist. Intensive Care Med 2009;35(10):1809-1814.

7. Barwing J, Pedroni C, Quintel M, Moerer O. Influence of body position, PEEP and intra-abdominal pressure on the catheter positioning for neurally adjusted ventilatory assist Intensive Care Med 2011;37(12):2041-2045.

8. Lee J, Kim H, Jung Y, Shin S, Choi C, Kim E, et al. Noninvasive neurally adjusted ventilatory assist in preterm infants: a randomised phase II crossover trial. Arch Dis Child Fetal Neonatal Ed 2015; 100(6):F507-513.

9. Gibu CK, Cheng PY, Ward RJ, Castro B, Heldt GP. Feasibility and physiological effects of noninvasive neurally adjusted ventilatory assist in preterm infants. Pediatr Res 2017;82(4):650-657.

10. Janvier A, Khairy M, Cormier C, Messmer D, Barrington K. Apnea is associated with neurodevelopmental impairment in very low birth weight infants. J Perinatol 2004;24(12):763-768.

11. Badier M, Jammes Y, Romero-Colomer P, Lemerre C. Tonic activity in inspiratory muscles and phrenic motoneurons by stimulation of vagal afferents. J Appl Physiol 1989;66(4):1613-1619.

12. Widdicombe JG. Head's paradoxical reflex. Exp Physiol 1967;52: 44-50.

13. Abu-Shaweesh JM, Martin RJ. Neonatal apnea: what's new? Pediatr Pulm 2008;43(10):937-944.

14. Mathew OP. Apnea of prematurity: pathogenesis and management strategies. J Perinatol 2011;31(5):302-310.

15. Wycoff MH, Aziz K, Escobedo MB, Kapadia VS, Kattwinkel J, Perlman JM, et al. Neonatal Resuscitation: 2015 American Heart Association Guidelines Update for Cardiopulmonary Resuscitation and Emergency Cardiovascular Care. Circulation 2015;132(18 Suppl 2):S543-560 